\title{
O FENOMMENO DAS COMPRAS \\ COLETIVAS PELA INTERNET: O CASO PEIXE URBANO
}

THE PHENOMENON OF COLLECTIVE INTERNET BUYING: THE CASE OF PEIXE URBANO

EL FENÓMENO DE LAS COMPRAS COLECTIVAS POR LA INTERNET: EL CASO PEIXE URBANO

Ana Paula Kieling

Mestranda

Universidade Federal de Santa Catarina anakieling@gmail.com

\section{Maria Luiza da Silva Costa}

Especialista

Universidade do Vale do Itajaí marialuiza@tatticas.com.br

Maycon Pierre Til

Especialista

Universidade do Vale do Itajaí maycon_til@hotmail.com

Ricardo Boeing da Silveira

Doutor

Universidade do Vale do Itajaí boeing@univali.br

Submetido em: 17/01/2012

Aprovado em: 15/01/2013

\section{RESUMO}

As compras coletivas surgiram no Brasil em meados de 2010 e rapidamente fixaram-se como uma forte fonte de publicidade digital ao intermediar relações entre clientes e empresas na modalidade de comércio digital de produtos e serviços. Seu diferencial consiste em ofertar vantagem a seus stakeholders - clientes e investidores, seja por meio de descontos nas compras, como por meio de marketing digital. O caso em questão aborda o tema ao ilustrar o comportamento de uma estudante brasileira adicta ao website Peixe Urbano, portal da Internet que incorporou o país ao fenômeno das compras coletivas, e levará o leitor a compreender e questionar as nuances do mercado digital, bem como a forte influência do comércio eletrônico como base do negócio.

PALAVRAS-CHAVE: Compras coletivas. Comércio eletrônico. Marketing digital.

\begin{abstract}
Collective buying emerged in Brazil in the middle of 2010, and quickly becamse established as a strong source of digital marketing, by intermediating relationships between customers and companies in products and services through the digital commerce of products and services. Its unique characteristic is that it offers an advantage to its stakeholders - customers and investors, either through discounts on purchases, and through digital marketing. The case study in question addresses the subject by illustrating the behavior of a brazilian student addicted to Peixe Urbano, a website that introduces the country to the phenomenon of collective buying, and will lead the reader to understand and question the nuances of the digital market, and the strong influence of e-commerce as a business option.
\end{abstract}


KEYWORDS: Collective buying. E-commerce. Digital marketing.

\section{RESUMEN}

Las compras colectivas surgieron en Brasil a mediados de 2010 y se fijaron rápidamente como una importante fuente de publicidad digital al intermediar relaciones entre clientes y empresas en la modalidad de comercio digital de productos y servicios. Su diferencial consiste en ofrecer ventajas a sus stakeholders - clientes e inversionistas-, ya sea por medio de descuentos en las compras o por medio de marketing digital. El caso en cuestión aborda el tema al ilustrar el comportamiento de una estudiante brasileña adicta al website Peixe Urbano, portal de Internet que incorporó el país al fenómeno de las compras colectivas, y llevará al lector a comprender y cuestionar los matices del mercado digital, así como la fuerte influencia del comercio electrónico como base del negocio.

PALABRAS CLAVE: Compras colectivas. Comercio electrónico. Marketing digital.

\section{INTRODUÇÃO}

Dormir tarde e acordar cedo - esta é a rotina de Daiana, 19 anos, estudante de Publicidade e Propaganda de uma universidade privada carioca. O motivo? Não se trata de trabalho ou estudo, mas sim um vício: as compras coletivas.

Há menos de dois anos atrás, em abril de 2011, Daiana buscava opções de restaurantes por meio da Internet para festejar seu aniversário entre amigos e se deparou com um site desconhecido - o Peixe Urbano, que a atraiu por oferecer grandes descontos em estabelecimentos de lazer.

O portal Peixe Urbano, pioneiro do negócio de compras coletivas no país, foi criado em 2010 por um brasileiro de 29 anos radicado nos Estados Unidos com a ajuda de dois amigos. Júlio Vasconcellos investiu na ideia a partir de um forte desejo de empreender em um ramo ainda pouco explorado no país. Em sua pesquisa, percebeu a dificuldade em encontrar na Internet informações sobre o que estava acontecendo no Rio de Janeiro - informações simples e úteis, como aonde ir, o que comer e o que fazer: bons lugares para jantar, hotéis a serem visitados, centros de serviço em saúde e estética.

\section{A DISSEMINAÇÃO DO CONCEITO DE COMPRA COLETIVA}

Em 2010, o conceito de compras coletivas dava seus primeiros passos no Brasil, enquanto nos Estados Unidos o website GroupOn já fazia sucesso com a divulgação de descontos em bens de consumo e serviços.

Daiana nunca tinha ouvido falar na febre norte-americana, mas quando entrou no portal Peixe Urbano e viu uma infinidade de ofertas à sua disposição, sentiu que o Brasil sucumbiria rapidamente. Contudo ela precisava saber se aquilo funcionava: comprou dois cupons que valiam um desconto de $65 \% \mathrm{em}$ um restaurante. Como sua compra só seria validada se mais 280 pessoas a adquirissem, decidiu disseminar a oferta para seus amigos por meio da Internet e de mensagens de texto pelo celular.

De fato, este foi o pensamento de Júlio, sociofundador, ao criar o website: impulsionado pela ideia de que brasileiro adora promoção e é um ser extremamente social, direcionou seu negócio rumo ao sucesso. O portal, baseado em serviços de e-commerce que agregam valor ao cliente por meio de experiências diferenciadas com preços muito abaixo do mercado, começou com acesso de amigos e conhecidos dos criadores e, em 2012, já conta com mais de 20 milhões de clientes cadastrados.

Para garantir que seus amigos topariam se inscrever em um website que enviaria muitos e-mails a suas contas de correio eletrônico e comprariam com seus cartões de crédito através da Internet, 
Daiana decidiu escrever um e-mail em que contava que tinha feito a "descoberta do ano", explicava a dinâmica de compras e que gostaria muito que seus amigos se cadastrassem. No e-mail ela também citou exemplos de ofertas disponíveis e pediu que os amigos se cadastrassem, mesmo que não comprassem nada em um primeiro momento. Assim, receberiam as promoções através de e-mails e ela receberia um bônus em compras por cada cadastro efetuado por meio de indicação.

Horas depois, a estudante recebeu a notícia que seu pedido havia sido confirmado para a primeira de muitas compras que ainda se concretizariam. Para ela, o site oportunizou momentos e experiências que talvez ela nunca desfrutasse se os produtos e os serviços estivessem com o preço real.

\section{TRILHANDO O CAMINHO DA INOVAÇÃO}

O destaque que Julio Vasconcelos obteve se deu justamente pelo pioneirismo de lançar o primeiro site de compra coletiva do país. O Brasil é um dos líderes mundiais em consumo de Internet e o comércio eletrônico estava no auge em 2010, atingindo a marca de 20 milhões de pessoas que efetuaram pelo menos uma compra pela Internet já no primeiro semestre do ano, gerando um aumento de quase $45 \%$ no faturamento, se comparado ao mesmo período do ano anterior, segundo dados do portal e-Bit Informações.

Uma pesquisa realizada no ano de 2010 pelo Instituto Ibope Nielsen Online identificou que, no mês de setembro do mesmo ano, 5,6 milhões de internautas já haviam visitado páginas de sites de compras coletivas pelo menos uma vez. Isso indica que $10 \%$ dos usuários de Internet do país já estavam conectados a essa novidade apenas seis meses após o lançamento do Peixe Urbano, embalados não somente pelas ofertas do portal, mas também por outros websites do gênero que surgiram na sequência.

Quatro meses depois de arrematar sua primeira oferta, Daiana já tinha duas pastas cheias de vouchers - alguns que talvez nunca usasse, outros talvez já vencidos. Ao mesmo tempo em que seu vício aumentava, o número de adeptos ao e-commerce atraídos pelo fenômeno das compras coletivas crescia incessantemente. Em 2011, dezenas de novas filiais do Peixe Urbano foram abertas em todo o país e na América Latina, impulsionadas por novas parcerias contratadas para que o consumidor esteja sempre satisfeito, afinal, com o aumento da concorrência, de nada adianta atrair novos clientes se não há capacidade para mantê-los com qualidade adequada.

De fato, ao falarmos em marketing digital, sabe-se que investir é o diferencial do negócio. Apesar de a modalidade compras coletivas oferecer opções de publicidade com baixo custo às empresas, sem investimento estratégico em marketing de Internet os negócios tendem a não prosperar. As corporações que escolhem veicular seus produtos e serviços em sites de compras coletivas na verdade estão optando por dedicar seus esforços publicitários ao público-alvo do mercado digital. Neste cenário figuram não somente os concorrentes - centenas de websites genéricos que pipocam todos os dias - como também os concorrentes indiretos: outros sites que atingem o público em questão por meio de apelos diferentes, como é o caso do serviço de microblog Twitter, que hoje é palco de publicidade paga atrelada a grandes nomes da televisão, funcionando no sistema boca a boca virtual, por meio da troca de links entre perfis corporativos e usuários.

Assim, os mesmos canais que ajudam a disseminar o Peixe Urbano para seus clientes podem também absorver por completo possíveis novos parceiros. Apesar de muitas vezes os serviços serem utilizados concomitantemente, as empresas tendem a decidir por investir alto em publicidade em apenas uma ou duas ferramentas digitais, para evitar saturamento da marca neste nicho de mercado. Ou seja, o empresário acaba optando por investir seus ativos ou no Facebook, ou no Twitter ou somente em sites de compras coletivas. A relação atual de concorrência integrada entre os canais de mídia digital é no mínimo interessante e só prova que o marketing gerado pelo movimento de e-commerce veio com força total e não admite mais movimentos amadores de seus investidores.

\section{OS DESAFIOS DE UM NOVO SEGMENTO DE MERCADO}

Entretanto nem tudo são flores no mundo do comércio digital aliado às compras coletivas. Com consumidores cada vez mais conscientes de seus direitos, e conectados à Internet com acesso a uma 
fonte inesgotável de informação, as empresas ficam suscetíveis às críticas e às falhas disseminadas pelo país todo com rapidez.

Com o número de filiais aumentando no Brasil, o Peixe Urbano agora possui mais um novo desafio: manter a qualidade de serviço de todos os seus parceiros, pois começam a difundir pela Internet comentários de atendimento não satisfatório em alguns dos estabelecimentos anunciados e até mesmo rumores de discriminação com clientes que possuíam o ticket de consumo vendido por meio do portal. Ainda que haja um grande aumento nas reclamações desde a criação do site, de acordo com o Peixe Urbano, elas possuem índice de solução próximo a 90\%, o que indica preocupação e respeito pelo consumidor por parte da empresa.

O primo de Daiana, residente da cidade de São Paulo, foi um dos consumidores que se sentiram lesados por um website de compras coletivas. Ao informar que iria utilizar um ticket de desconto em um restaurante paulistano, o rapaz se deparou com olhar de desprezo do garçom e sentiu-se discriminado por não pagar o valor total da conta. Para ele, o desconto não vale a pena - o jovem hoje diz que prefere ficar em casa a ser mal tratado por um serviço que ele tem direito a usufruir. Assim como no caso dele, outros consumidores sentiram-se lesados com compras malsucedidas e esse se tornou um tópico cujo website passou a estar constantemente atento, estreitando assim seu relacionamento com os clientes.

Essa conexão intensa com os consumidores da web também faz com que um site deste segmento pense rápido: em outubro de 2010, o Peixe Urbano vendeu mais de 30.000 unidades de uma única oferta, que oferecia um sanduíche e um bolo por preços mínimos. Já em novembro de 2010, o site promoveu uma semana especial com venda de roupas - segmento de mercado inédito em suas promoções e no mês de fevereiro de 2011 foi a primeira empresa do país a anunciar no Twitter através dos Trending Topics, conforme informado pelo site Info Online em fevereiro de 2011. Estes movimentos mostram que a empresa adotou uma postura agressiva e continua vendendo em grande escala, apesar dos problemas recorrentes na relação entre cliente-final e investidor.

\section{O MAR ESTÁ PARA PEIXE, MAS... ATÉ QUANDO?}

Daiana dorme depois da meia-noite e acorda antes das oito da manhã e o motivo é um só: acompanhar as primeiras ofertas do dia veiculadas no Peixe Urbano - se antes o empenho era para divulgar as ofertas para que alcançassem a cota necessária de pessoas para ativá-la, agora a corrida é para conseguir comprar antes que o número de produtos ou serviços se esgote. Além disso, é assim que ela se informa e tem sempre novidades para repassar aos amigos sobre o que há de interessante para fazer na cidade.

Para a estudante, um fator que contribuiu para a solidificação do website Peixe Urbano foi o aumento do número de consumidores pela Internet. Um dos motivos ligados a isso é a facilidade para aquisição de um computador, devido ao aquecimento da economia brasileira e às facilidades de crédito. Aliado a isso, um mercado com potencial de crescimento, pois apesar de haver um aumento na aquisição de máquinas, a maioria da população brasileira ainda não possui acesso à rede mundial de computadores - a Internet.

E Daiana está certa. Segundo dados publicados pelo e-Bit Informações, após o boom da Internet, e-commerce e compras coletivas dos últimos anos, o Brasil somou mais de 94 milhões de usuários em 2012, atingindo a 5 a posição mundial em número de pessoas conectadas à Internet.

Entretanto muitos consumidores que utilizam sites de compras coletivas acabam por adquirir um produto ou serviço baseado apenas no valor da oferta, ou seja, aproveitam a promoção mesmo que, no momento, o bem ou o serviço adquirido não seja de sua necessidade. Perceba que o perfil de Daiana se encaixa no que estamos falando: este é o tipo perfeito de consumidor para os sites de compras coletivas - o que compra por impulso. Ao realizar uma compra pela Internet, o consumidor não só está adquirindo um produto como para fazê-lo é necessário estar cadastrado. Essa é uma ferramenta chave neste nicho de mercado, pois o cliente passa informações valiosas, como seu perfil de consumo, idade, região, escolaridade e, ao navegar e clicar em determinados links de ofertas, sem perceber fornece outras informações não menos importantes sobre o que aquele perfil está procurando na rede, o que ajuda a criar ofertas e promoções direcionadas a um público-alvo, tornando o marketing muito mais assertivo. 
Daiana, como boa estudante de Publicidade e Propaganda, não parou suas pesquisas por aí. Diariamente ela acompanha não só as ofertas divulgadas, como uma infinidade de notícias veiculadas sobre o tema. Atenta aos movimentos do mercado, ela quer entender os porquês, desde as motivações de compra dos consumidores, passando por questões de gestão de relacionamento, até mesmo saber quem coloca em perigo a existência destes portais. O que faz o negócio girar? Quem vende e por quê? Quem compra? São estas as dúvidas que quem aprova o negócio quer sanar, pois mais do que nunca, o cliente deseja protagonizar todo processo, do início ao fim.

As compras coletivas caíram no gosto do consumidor brasileiro e sabemos que existem muitas Daianas espalhadas pelo Brasil afora - afinal, todos querem fazer parte de um grupo e saber das últimas novidades sobre o que acontece em sua cidade em tempo real. Sem pedir licença, o portal Peixe Urbano popularizou o consumo via Internet e até mesmo aqueles que nunca haviam comprado algo pela rede agora se sentem a um passo da - fácil - decisão de compra.

Desta forma, o Peixe Urbano colhe os louros da inovação no ramo do e-commerce e ao mesmo tempo tenta se equilibrar na corda bamba da economia brasileira. Neste cenário, resta saber como será possível que o portal mantenha seu reinado perante um consumidor cada dia mais exigente, permaneça na cabeça dos donos de estabelecimentos comerciais como um mercado potencial e ainda se posicione adequadamente frente aos inúmeros riscos que surgem no dia a dia de empresas que lidam com marketing virtual e comércio eletrônico. Em outras palavras, a grande dúvida que permeia o assunto é: até quando este mar estará para peixe?

\section{NOTAS DE ENSINO}

\section{OBJETIVOS EDUCACIONAIS}

O caso em questão enfatiza a força do fenômeno das compras coletivas, uma modalidade de venda proveniente do comércio digital extensamente difundida no país desde 2010. Como objetivo de aprendizagem, tem como intenção desenvolver nos participantes novos conhecimentos sobre 0 tema de comércio digital, comportamento do consumidor e relações com stakeholders.

\section{FONTES DE DADOS}

Este caso relata o surgimento e o crescimento de uma empresa direcionada ao comércio eletrônico na modalidade compras coletivas por meio das experiências de um consumidor adicto à atividade de compra. Apesar de utilizar como ferramenta expositiva a presença de um personagem fictício, as situações relatadas no caso são fiéis à realidade pesquisada. Os dados e as informações coletadas são de caráter primário, sendo utilizadas técnicas de entrevista e informações provenientes da empresa objeto de estudo, complementadas por uma análise do caso e sua da conexão com a literatura.

\section{QUESTÕES PARA ESTUDO}

Por que os e-consumidores aderiram à febre das compras coletivas no Brasil e qual foi o papel do Peixe Urbano neste cenário?

Quais obstáculos mercadológicos o Peixe Urbano deverá enfrentar nos próximos anos?

Quanto aos domínios do marketing digital, como é possível inovar e empreender no ramo de compras coletivas? Neste contexto, como o Peixe Urbano obteve destaque até o presente momento? 


\section{ANÁLISE DO CASO E CONEXÃO COM A LITERATURA}

\section{Relacionamento com clientes e parceiros}

Os e-consumidores estão em busca de preços baixos e conveniência na hora de optar pela compra on-line e trocam informações a fim de otimizar o seu tempo (FERNANDES, 2010). Eles estão sempre em busca de novidades: lugares novos, comidas diferentes e passeios inusitados - os sites de compras coletivas trazem a possibilidade de ter essas situações pela metade do preço, retendo cada vez mais clientes.

Neste contexto, as características dos websites de compras coletivas relacionam-se diretamente com as tendências de mercado do e-commerce citadas por Kalakota e Robinson (2002): proporcionam um serviço de autoatendimento ágil e rápido, diversas opções de produtos e oferecem soluções integradas de serviços dentro de um mesmo local. De acordo com Vieira (1999), o consumidor passa por sete etapas durante o processo de compra na rede: comodidade, atendimento, conteúdo informacional do site, layout da homepage, segurança, taxa de tempo e entrega e oferta de produtos. Estas mesmas etapas valem para os sites de compras coletivas, e todas estas etapas são percebidas nos processos desenvolvidos no Peixe Urbano, pioneiro nas ações do gênero no Brasil.

Blessa (2005) cita o preço promocional como uma das possibilidades de alavancar as vendas de produtos ou serviços. Os sites de compras coletivas atuam nesse âmbito, oferecendo valores com descontos aos consumidores e propiciando um espaço de promoção de vendas aos seus parceiros. A promoção de venda é um incentivo extra para a compra do produto, que causa impacto e tem como objetivo conduzir o cliente à compra imediata.

De fato, o Brasil despontou nos últimos anos como um mercado promissor na área de comércio eletrônico, devido à alta adesão de consumidores por ano e aceitação percebida da modalidade de compra e venda. A entrada do Peixe Urbano no mercado de seis países da América Latina com tão pouco tempo de existência da empresa é um indicativo de que as oportunidades provenientes do e-commerce brasileiro estão sendo bem aproveitadas em âmbito internacional. No início de 2011, o website de consultoria em comércio eletrônico E-Vision realizou uma pesquisa relatando detalhes importantes sobre quem consome produtos e serviços oferecidos em sites de compras coletivas, que confirmam alguns indicadores citados anteriormente:

- Ofertas com mais de $60 \%$ de desconto (independente do preço original) vendem muito: elas indicam uma oportunidade muito boa de venda e ativam o comportamento impulsivo dos consumidores.

- Produtos com valor mais de $R \$ 200,00$ têm mais dificuldade de venda: quanto mais alto o valor percebido pelo consumidor, menores são as chances de uma compra impulsiva ser efetuada.

- Produtos sazonais podem chegar a ótimos preços fora de temporada e são venda certa: oportunidade diferenciada por preços especiais - a receita do sucesso para o público-alvo.

De fato, os websites de compras coletivas já conquistaram seu espaço no Brasil e no mundo, porém é importante que, em trabalho conjunto com os estabelecimentos que são anunciados, estejam cientes de que o foco das operações de venda deve ser o cliente. Este é um dos principais diferenciais notados em portais de ponta como o Peixe Urbano com relação às empresas de compra coletiva de menor porte. Isso se dá pela percepção de que, no momento em que se perde um cliente, não está se perdendo apenas uma venda, mas sim todas as demais potenciais compras que ele faria durante toda vida, além de indicações que ele daria sobre a empresa (BEE; BEE, 2000). Os estabelecimentos que ofertam em sites de compras coletivas precisam ter ciência de que, ao anunciar, conquistarão potenciais clientes, mas não estarão vendendo para lucrar. Apesar de reconhecido como carro-chefe do portal Peixe Urbano e de outros websites do ramo, é visto que o preço promocional já não basta para garantir que um portal de compras coletivas obtenha sucesso no país. Prova disso são os inúmeros negócios virtuais que abriram no auge da febre das compras coletivas e que acabaram por fechar suas portas.

Como a satisfação dos clientes deve estar sempre em primeiro lugar, é importante ter uma excelente estratégia pós-venda, principalmente para os clientes que entram em contato com o SAC 
da empresa. O pós-marketing, mais conhecido como serviço de pós-venda, tem como objetivo manter os clientes satisfeitos com a compra, aumentar a probabilidade de novas aquisições, oferecer a percepção de cuidado aos clientes, deixar perceptível que a empresa está atenta à sua satisfação (VAVRA, 1993). O bom atendimento e a empatia são importantíssimos quesitos nessa situação, pois transformarão uma experiência ruim do cliente com o parceiro em uma boa experiência do cliente com o website (BERRY; PARASSURAMAN, 1992). Esta confiança e segurança são primordiais para que o consumidor continue adquirindo ofertas com frequência e este diferencial tornou-se um dos pilares para manter o Peixe Urbano em pé nessa corrida pelos consumidores.

Porém, como a equipe do portal pode controlar como seus parceiros administram as vendas e os clientes provenientes das transações feitas por meio do portal? Com consumidores cada vez mais críticos e a concorrência cada vez maior, o website Peixe Urbano deve manter um padrão de qualidade de atendimento pós-venda satisfatório para seus consumidores, ainda que isso implique um processo bastante seletivo de escolha de parceiros anunciantes. Parasuraman, Zeithanl e Berry (1985) citam cinco procedimentos que devem ser implantados a todas as organizações para que se solidifique um bom padrão de prestação de serviços: manter e desenvolver padrões de pesquisa com foco nas necessidades e expectativas dos clientes; criar projetos que atendam a essas expectativas; implementar os projetos e transformá-los em especificações e padrões de serviços; atender a essas especificações criadas; e não criar expectativas no consumidor que não possam ser cumpridas. Nesse âmbito, os sites de compras coletivas precisam estar atentos e manter seus colaboradores preparados e ágeis para atender à expectativa de quem entra em contato, pois na maioria das vezes são clientes que não obtiveram uma boa experiência com o serviço prestado pelo parceiro.

A satisfação dos clientes pode ser mensurada de diversas formas, conforme citado por Freitas (2005): formulários de pesquisa, entrevistas, urnas de sugestões, pesquisa de mercado, serviço de atendimento ao consumidor e mesa redonda com o cliente. Desses citados, três elementos são simples e fáceis e devem ser utilizados por sites de compras coletivas. Segundo Vavra (1993), a insatisfação com o produto o serviço, a falta de importância com a reclamação feita e a mudança de políticas da empresa são os principais motivos que fazem um consumidor desistir de efetuar uma segunda compra. O amparo dado hoje pelo sistema de SAC dos sites de compras coletiva é essencial para que o sucesso das compras coletivas continue. Clientes que saem insatisfeitos após a utilização de um produto ou serviço são capazes de falar sobre a experiência a uma média de dez pessoas, enquanto clientes satisfeitos não costumam repassar a informação espontaneamente (CANNIE, 1995).

Mesmo com o risco presente de comprometer-se em um negócio no qual o portal atua como intermediário entre parceiro e cliente, pesquisas realizadas pelo e-Bit Informação em 2012 apontam que a aprovação dos consumidores é maior relacionada ao portal de compras coletivas do que relacionada ao parceiro que faz a venda direta. Isso significa que os cuidados e o profissionalismo apresentados pelos principais portais de compras coletivas do país têm gerado resultados positivos, desvinculando parte da responsabilidade do portal no caso de um cliente sair insatisfeito de uma compra feita no site.

\section{Desafios e Oportunidades do Marketing Digital}

O comércio digital, fruto da integração entre tecnologia e comunicação, envolve os processos de compra e venda realizados por meio da internet (NETO, 2003). Modalidade de venda recente no Brasil, com cerca de 15 anos de presença no mercado, o e-commerce atualmente passa por um período de crescimento desenfreado em que busca de maneira concomitante qualificar e profissionalizar seus serviços, apoiando-se em órgãos regulamentários que atuem a seu favor.

É pertinente dizer que as compras coletivas deram novas nuances ao comércio eletrônico e despertaram aos olhos de consumidores e organizações uma grande oportunidade de desfrutar de vantagens antes desconhecidas e, ao avaliarmos o cenário deste segmento mais a fundo, fica clara a importância crucial do marketing para sustentar mais uma etapa de consolidação deste modo de comercialização. O crescimento nas vendas pela web fez com que as empresas percebessem a necessidade de estudar o mercado digital e analisar suas potencialidades com fins práticos. De acordo com Cintra (2010), essa nova tendência faz com que as propagandas estejam cada vez mais criativas e atualizadas, o que desencadeia no usuário interesse pela empresa. 
Entretanto é evidente que a Internet está longe de ser um sonho e o comércio eletrônico ainda oferece riscos tanto às corporações quanto aos consumidores, assim como o marketing digital é oscilante e pode tanto elevar uma organização ao topo quanto arruiná-la em questão de segundos.

Um dos principais obstáculos a ser enfrentado pelo Peixe Urbano no futuro está em obedecer aos princípios éticos como corporação, visto o alto grau de manipulação de dados que a empresa possui em um cenário cuja privacidade é uma das grandes questões críticas a serem levantadas. Prevendo tais riscos em seu mercado, a Associação Americana de Marketing já desenvolveu um código de ética para o marketing digital, em que aponta que a informação recolhida junto de clientes deve ser confidencial e utilizada somente para fins expressamente identificados, segundo Rita e Oliveira (2006). Nesta linha, a participação ativa do Peixe Urbano como membro de Comitê de Compras Coletivas da Câmara Brasileira de Comércio Eletrônico, juntamente a seus concorrentes mais fortes no mercado, que somam juntos $85 \%$ das vendas em compras coletivas, vem sendo colocada em prática desde 2011. Assim, para manter-se no mercado, o portal deve continuar aliando seu nome a práticas positivas e respeitar os limites no relacionamento com seus clientes.

Outro fator que deve ser observado como crítico é o aumento da concorrência no cenário digital brasileiro. Sabe-se que $70 \%$ do poder de compra global e $92 \%$ da população mundial vivem em países no qual o Inglês não é a língua nativa (DUNLAP, 2000). Com o poder de compra ampliado em países como o Brasil, surgem inúmeros websites de venda pela Internet e, com o tempo, será a qualidade do serviço que determinará os protagonistas da rede, afinal, a preocupação com a segurança das transações e os atrasos na entrega dos produtos já têm levado milhares de pessoas a optarem por utilizar a Internet apenas para comparar produtos e preços, eliminando assim a ação de compra.

Ao optar por uma seleção rígida no que diz respeito a novas parcerias, é como se o Peixe Urbano estivesse fazendo o "dever de casa" no que diz respeito à\ transparência e à qualidade no negócio, evitando ao máximo a possibilidade de algo sair errado.

Entretanto, em um cenário cujos consumidores que promovem protestos diários contra empresas criando websites próprios com intuito de disseminar comentários negativos referente a serviços e produtos coabitam lado a lado a grandes corporações (RITA; OLIVEIRA, 2006), o maior desafio é, sem dúvida, sobreviver ileso e manter-se no topo. A mídia interativa, modalidade largamente utilizada pelo Peixe Urbano, soa como uma revolução para muitas empresas, pois permite que os profissionais da área entreguem em tempo real serviços e conteúdo personalizado. Assim, o marketing digital aproveita as exclusivas características da mídia interativa: é endereçável - ou seja, cada usuário pode ser identificado e tratado de maneira individual, trata-se de um relacionamento de dois lados e o processo completo de compra pode ser feito on-line (KIERZKOWSKI; MCQUADE; WAITMAN; ZEISSER, 1996),

Neste contexto, é interessante perceber que os websites de compra coletiva não estão sozinhos na prática do marketing digital. De acordo com Yanaze (2006), a concorrência não se limita apenas a portais que oferecem os mesmos serviços e, para que uma empresa possa criar e sustentar uma vantagem competitiva, é fundamental identificar e conhecer seus concorrentes. Segundo Bateman e Snell (1998), concorrência é quando as organizações competem pelos mesmos consumidores e tentam ganhar participação de mercado. Desta maneira, lojas on-line, páginas virtuais de relacionamento, ferramentas de microblog e portais de Internet que disseminam vídeos são alguns dos agentes que disputam os olhares do consumidor no ambiente virtual. Considerando a literatura discutida e o caso em questão, uma estratégia de diferenciação para o portal Peixe Urbano seria resgatar o fator determinante de seu sucesso inicial, exaltando a questão do pioneirismo do website no cenário das mídias sociais. 0 fato, que garantiu solidez e confiança dos seus consumidores em um primeiro momento, é um ativo a ser usado tanto para reter parcerias de empresas com grande credibilidade perante os consumidores, quanto para reforçar a imagem do portal buscando encantar os clientes finais.

As redes sociais da Internet vêm se estruturando ao longo do tempo como verdadeiras potências em marketing digital. O website de micro-blogging Twitter já é reconhecido como uma ferramenta de marketing boca a boca virtual (do inglês E-Word of Mouth) entre pequenas e médias empresas por disseminar marcas em mensagens publicitárias curtas para as grandes massas (BULEARCA, 2010). Já o portal de relacionamento Facebook dá às empresas a possibilidade de divulgar serviços, produtos, notícias atualizadas e conteúdo relevante sobre si. Estima-se que $40 \%$ dos consumidores afiliem-se a páginas de marcas no Facebook para mostrar interesse no serviço ou no produto oferecido. Em 
contrapartida, cerca de $40 \%$ dos consumidores que recebem e-mail-marketing de corporações deixem de comprar de marcas que enviam informações consideradas irrelevantes (MARIES, 2011).

Como se vê, apesar da existência e da diversificação de concorrentes frente às praticas de divulgação das compras coletivas, a linha entre erro e acerto ainda parece bastante tênue no que diz respeito a estratégias de marketing digital. Esta modalidade traz a oportunidade que muitos esperam para inovar no mercado tradicional, em que tudo era feito com prazos e regras; neste novo cenário leva-se em consideração a comodidade, a agilidade e a facilidade do relacionamento entre cliente e empresa, e é por este motivo que os serviços on-line conquistam cada vez mais espaço, fazendo com que marcas sejam lembradas e fidelizando consumidores satisfeitos com os serviços oferecidos. Este tipo de promoção tornou-se uma opção inovadora com custo menor e alta projeção, cujas empresas podem oferecer de modo fácil e rápido seu produto, agradando a diversos nichos de clientes e fixando sua marca no mercado (CINTRA, 2010).

Mesmo com as diversas discussões que afirmam que a Internet trouxe consigo uma reinvenção da gestão mercadológica, é importante frisar que o marketing digital não é um novo marketing, mas sim um conjunto de estratégias alocadas no ambiente digital que utilizam ferramentas de marketing já conhecidas, tais como publicidade, propaganda, comunicação e várias outras teorias do marketing que ficam a serviço do gestor para a montagem do plano digital de marketing (TORRES, 2009).

Sem dúvida, uma das grandes oportunidades de inovação no mercado da Internet atualmente encontra-se no fácil acesso a mercados internacionais, que no passado eram virtualmente inatingíveis por muitas organizações e agora parece não ter mais limites geográficos (BECKER, 2002). De fato, se atentarmos que a palavra Internet deriva de internetworking, ou seja, a ação de conectar redes separadas, esta teoria só vem a ser reforçada, afinal sabe-se que a internet é a maior e mais conhecida rede interligando milhares de outras redes individuais no mundo (LAUDON; LAUDON, 2007), o que representa uma abrangência que vem se ampliando gradualmente no mundo dos negócios. Esta característica é explorada pelo Peixe Urbano desde o início de 2011, quando as operações estenderam-se à América Latina e aos Estados Unidos. Com a participação em mercados com perfis diferentes do brasileiro, a empresa deve se reinventar e adaptar-se ao modelo de negócio dos demais países, sem perder a essência.

Também como estratégia de inovação no campo do marketing digital é interessante destacar como ferramenta a técnica do benchmark, que consiste em buscar referenciais de sucesso e melhores práticas do mercado para gerar um processo de pesquisa comparativo que poderá suscitar em aperfeiçoamento empresarial ou mesmo novos ativos. Entretanto, para que seja possível utilizar os processos desenvolvidos por outras organizações sem tornar-se mera cópia, é essencial agregar valor e personalidade ao serviço a ponto de que o mesmo se torne um destaque em seu segmento, afirmam Jutla, Bodorik e Wang (1999). De certo forma, evidencia-se que o Peixe Urbano absorveu o conceito de prestação de serviços oferecido pelo GroupOn nos Estados Unidos, fazendo benchmark ao processar informações para dar origem a uma empresa que se destaca pela singularidade, que se adequou aos padrões de consumo brasileiro. Do mesmo modo, outras práticas internacionais poderão servir como base para aperfeiçoar processos e serviços da empresa.

Apesar das compras coletivas serem consideradas um fenômeno mercadológico, o futuro do Peixe Urbano ainda é incerto. Como a fórmula tende a se desgastar com o passar dos anos e com a recorrência de problemas entre parceiro e cliente final, a empresa demanda reinvenção constante, investimento em tecnologia de ponta e foco em qualidade do serviço, seja por meio do próprio website, como por meio da triagem e monitoramento de parcerias. Afinal, para que o gigante das compras coletivas no Brasil não morra na praia, é necessário bem mais do que um cardume fiel.

\section{REFERÊNCIAS}

BATEMAN T.; SNELL, S. Administração: construindo vantagem competitiva. São Paulo: Atlas, c. 3, p. $69-85,1998$

BECKER, S. A. An exploratory study on web usability and the internationalization of US e-businesses, Journal of Electronic Commerce Research, v. 3, n. 4, p. 265-278, 2002.

BEE, F.; BEE, R. Fidelizar o cliente. São Paulo: Nobel, 2000. 
BERRY, L.; PARASURAMAN, A. Serviços de marketing: competindo através da qualidade. Maltese-Norma, São Paulo, 1992.

BLESSA, R. Merchandising no ponto-de-venda. São Paulo: Atlas, 2005.

BULEARCA, M. Twitter: a Viable Marketing Tool for SMEs? Global Business Management Research, v. 2 , n. 4, p. 296-310, 2010.

CINTRA, F. Marketing Digital: a era da tecnologia on-line. Revista Investigação, v. 10, n. 1, p. 6-12, 2010.

DUNLAP, B. Online Globalization: Sink or Swim. Disponível em: <http://www.glreach.com/eng/ed/art/ rep-eur22.php3>. Acesso em: 07/06/2011.

E-BIT INFORMAÇÕES. Relatório Webshoppers sobre e-commerce no Brasil. Disponível em: <http:// www.webshoppers.com.br/>. Acesso em: 28/12/2012.

E-VISION CONSULTORIA. Pesquisa sobre comportamento de compra na internet. Disponível em: < http://www.e-visionconsulting.com.br/>. Acesso em: 07/06/2011.

FERNANDES, L. O. Fatores que influenciam a intenção de compra Online: aplicação de um modelo adaptado de aceitação da tecnologia para o comércio eletrônico. Dissertação de Mestrado em Administração, Universidade Federal do Rio Grande do Norte, 2010.

FREITAS, A.L.P. A qualidade em serviços no contexto da competitividade. Revista Produção Online, v. 5, n. 1, p. 01-24, 2005.

INSTITUTO IBOPE-NIELSEN ONLINE. Pesquisa sobre Compras Coletivas. Disponível em: < http:// br.nielsennetpanel.com/pnl/br/home>. Acesso em: 02/06/2011.

JUTLA, D.; BODORIK, P.; WANG, Y. Developing internet e-commerce benchmarks. Information Systems - Special issue on information systems support for electronic commerce, v. 24, n. 6, p. 475-493, 1999.

KALAKOTA, R; ROBINSON, M. E-business: estratégias para alcançar o sucesso no mundo digital. 2. ed. Porto Alegre: Bookman, 2002.

KIERZKOWSKI, A; MCQUADE, S.; WAITMAN, R.; ZEISSER, M. Current research: marketing to the digital consumer. The McKinsey Quarterly, n. 2, p. 180-183, 1996.

LAUDON, K. C.; LAUDON, J. P. Sistemas de informações gerenciais: Administrando a empresa digital. São Paulo: Pearson Prentice Hall, 452 p., 2007.

MARIES, I. The Rise of Social Giants: Marketing Approaches for Companies Using the Facebook Communication Platform. Bachelor Thesis of Arts in Marketing and Management Communication, Aarhus School of Business and Social Sciences, University of Aarhus, 2011.

PARASURAMAN, A., ZEITHAML, V.A., BERRY, L.L. A conceptual model of service quality and its implications for future research. Journal of Marketing, v. 49, n. 4, p.41-50, 1985.

PEIXE URBANO, Portal de Compras Coletivas Online. Disponível em: http://www.peixeurbano.com. br. Acesso em: 09/01/2013.

RITA, P.; OLIVEIRA, C.. Manual: O marketing no negócio eléctrônico. SPI - Sociedade Portuguesa de Inovação, v. 1, 135 p., 2006. Disponível em: <http://web.spi.pt/negocio_electronico/documentos/ manuais_PDF/Manual_IV.pdf>.Acesso em: 12/06/2011.

TORRES, C. A bíblia do marketing digital: tudo que você queria saber sobre marketing e publicidade na internet e não tinha a quem perguntar. São Paulo: Novatec, 2009.

YANAZE, M. H. Gestão de Marketing: avanços e aplicações. São Paulo: Saraiva, 2006.

VAVRA, Terry G. Marketing de Relacionamento: after marketing. Atlas, São Paulo, 1993. 